\title{
QUANTITATIVE ANALYSIS OF ACETAMINOPHEN AND IBUPROFEN MIXTURE IN TABLET UTILIZING CENTERED AVERAGE ON SPECTRUM RATIO BY SPECTROPHOTOMETRIC TECHNIQUE
}

\author{
MUCHLISYAM BACHRI*, TUTY R P, EDWARD R \\ Department of Pharmaceutical Chemistry, Faculty of Pharmacy, Universitas Sumatera Utara Padang Bulan, Medan, 20155, Indonesia. \\ Email: muchlisyam@usu.ac.id
}

Received: 26 June 2018, Revised and Accepted: 07 August 2018

\begin{abstract}
Objectives: Centered average on spectrum ratio by spectrophotometric technique has been done validated for acetaminophen (ACT) and ibuprofen (IBU) in mixture. The goal of this research is to analyze concurrent determination of ACT and IBU mixture in tablet, using pH 7.2 phosphate buffer and ethanol (91:9) as solvent mixture.

Methods: The spectrophotometric technique was made by addition of standard solution from IBU, and the absorption spectrum of each drug has been recorded, which is divided by corresponding concentration as a dividing factor; after that, the centered flat of ratio spectra of ACT and IBU concentrations was determined by calibration graphs with measuring at obtained maximum wavelengths $244 \mathrm{~nm}$ for ACT and $221 \mathrm{~nm}$ for IBU.

Results: The research results showed that linearly correlation acetominophen and IBU are 3.0-9.0 $\mu \mathrm{g} / \mathrm{mL}$ and $5.0-13.0 \mu \mathrm{g} / \mathrm{mL}$, respectively, and linearly regression equations are $1.5800 \mathrm{X}+0.4809$ and $0.0991 \mathrm{X}+0.0205$ with coefficient correlation are 0.9962 and 0.9990 . Result of ACT and IBU in local tablet is $100.72 \pm 0.12 \%$ and $98.82 \pm 0.06 \%$ with the average of percentage recovery for ACT and IBU is $100.01 \%$ and $100.31 \%$, and relative standard deviation value is $0.03 \%$ and $0.06 \%$ respectively.
\end{abstract}

Conclusion: It can be concluded that centered average on spectrum ratio spectrophotometric technique is a smooth, accelerated, correct, and rigid for the analysis of ACT and IBU in mixture.

Keywords: Acetaminophen, Ibuprofen, Spectrophotometric technique, Centered average on spectrum ratio.

(c) 2018 The Authors. Published by Innovare Academic Sciences Pvt Ltd. This is an open access article under the CC BY license (http://creativecommons. org/licenses/by/4. 0/) DOI: http://dx.doi.org/10.22159/ajpcr.2018.v11i12.28093

\section{INTRODUCTION}

Acetaminophen (ACT) and ibuprofen (IBU) are the most common drug combination in analgesics and antipyretics preparation [1]. To achieve better quality control and safety, it is crucial in controlling the content of ACT and IBU in pharmaceutical tablets. ACT or 4-hydroxyacetanilide is a metabolite of phenacetin and considered as safe analgesic. ACT is sparingly soluble in water and used as a pain reliever in association of prostaglandin E2 reducer and lowers set point in hypothalamus [1].

IBU or 2-(4-isobutylphenyl)-propionic acid is nonsteroidal antiinflammatory drug used in rheumatoid arthritis and musculoskeletal disorder [2].

The chemical structure of ACT and IBU can be seen in Fig. 1a and b [2].

The presence of more than one active substances in drug can make a difficulty in assay analysis of each substance in pharmaceutical dosage form. The overlapped spectrum of each substance leads to this difficulty, and it is faced by applying a good simultaneous analysis method without prior separation and derivative steps [2]. Various methods have been published for the evaluation of ACT and IBU which are highperformance liquid chromatography and derivative spectrophotometry method [3].

Conventional spectrophotometric technique cannot resolve the drugs in their mixtures with impurities or other drugs, so several manipulations were performed to enable resolution of binary and ternary mixtures. Binary mixtures can be determined using different order derivatives, methods, manipulating ratio spectrator dual wavelength, mean centered of ratio (MCR) spectra, and spectrophotometric technique using metal ion [4-9].

MCR spectra were developed by Afkhami and Bahram [9]. It is a smooth, accelerated, correct, and rigid technique used to determine the mixture of mefenamic acid and ACT, and mixture of three drugs, namely acetosal, ascorbic acid, and paracetamol. Other researches about ratio spectra which have been published are to determine binary mixture of drug [10-13].

In addition, spectrophotometric methods have potential application in pharmaceutical analysis as they provide easy and efficient results for binary and ternary mixtures compared to conventional methods $[9,10-14,15]$.

The goal of this research is to apply centered flat of ratio spectra (CFRS) of spectrophotometric technique for the assay of ACT and IBU combination in pharmaceutical tablet using $\mathrm{pH} 7.2$ phosphate bufferethanol (91:9) as a solvent mixture and validation requirements such as accuracy and precision.

\section{EXPERIMENT}

\section{Instruments}

The spectrophotometric analysis of ACT and IBU by Shimadzu model 1800 double beam UV-Visible spectrophotometer with spectral bandwidth of $1 \mathrm{~nm}$ and wavelength accuracy of $0.1 \mathrm{~nm}$ (at $656.1 \mathrm{~nm} \mathrm{D2}$ ) was used to measure the absorbance of all the solutions. Software used in the study are Spectra spontaneously access by UV-Probe system software and MATLAB version 9.0. 


\section{MATERIALS AND METHODS}

\section{Materials}

Pharmaceutical grade of ACT was received from the Food and Drug Regulatory Agency of Indonesia (claimed purity of 100.31\%); IBU supplied by Sigma-Aldrich (claimed purity of $99.90 \%$ ); and ethanol absolute, sodium hydroxide, and potassium dihydrogen phosphate were purchased from Merck Ltd., Rudang, Medan, Indonesia. The product Indonesian local (contained $350 \mathrm{mg}$ of ACT and $250 \mathrm{mg}$ of IBU per tablet) was manufactured by PT Supra Ferbindo Farma, Tangerang, Indonesia.

\section{Methods}

Simultaneous determination of ACT and IBU mixture into a tablet using CFRS methods with a solvent mixture of phosphate buffer $\mathrm{pH} 7.2$ with ethanol (91:9) at the maximum wavelength of ACT was $243 \mathrm{~nm}$ (concentration of $6.6 \mu \mathrm{g} / \mathrm{ml}$ ) and of IBU was $222 \mathrm{~nm}$ (concentration of $8.0 \mu \mathrm{g} / \mathrm{ml}$ ). In the CFRS process and methods using MATLAB software and measurement value is obtained centered flat value. ACT mixture and IBU performed at a maximum wavelength of ACT was $244 \mathrm{~nm}$ (concentration of $7.0 \mu \mathrm{g} / \mathrm{mL}$ ) and of IBU was $221 \mathrm{~nm}$ (concentration of $9.0 \mu \mathrm{g} / \mathrm{mL}$ ). In assay preparation for tablet samples the addition of standard solutions of IBU as ingredients in is used, to match the ACT content ratio in the measurement, so that when IBU as a divisor would made absorbs of the concentrations has used in terms of Lamber-beer law in the area of 0.2-0.6 [15].

\section{Procedure of the experiment}

\section{Preparation of standard solutions}

An accurately weighed standard of $50 \mathrm{mg}$ ACT and $50 \mathrm{mg}$ IBU powder was transferred to separate $100 \mathrm{~mL}$ volumetric flasks and dissolved by pH 7.2 phosphate buffer-ethanol solvent mixture. The volume was made up to mark with the same solvent mixture to achieve a concentration of $500 \mu \mathrm{g} / \mathrm{mL}$ of each ACT and IBU (standard solution I). Then, each standard solution I was taken $5 \mathrm{~mL}$ and transferred to separated $100 \mathrm{~mL}$ volumetric flasks, to achieve $25 \mu \mathrm{g} / \mathrm{mL}$ of each (standard solution II) [15].

\section{Preparation of calibration solution}

The ACT standard solution II was pipetted each $1.2 \mathrm{~mL}, 2 \mathrm{~mL}, 2.4 \mathrm{~mL}$, $3.2 \mathrm{~mL}$, and $3.6 \mathrm{~mL}$ and transferred to $10 \mathrm{~mL}$ volumetric flasks to achieve concentration of $3 \mu \mathrm{g} / \mathrm{mL}, 5 \mu \mathrm{g} / \mathrm{mL}, 6 \mu \mathrm{g} / \mathrm{mL}, 8 \mu \mathrm{g} / \mathrm{mL}$, and $9 \mu \mathrm{g} / \mathrm{mL}$ The IBU standard II was pipetted each $2 \mathrm{~mL}, 2.8 \mathrm{~mL}, 3.6 \mathrm{~mL}, 4.4 \mathrm{~mL}$, and $5.2 \mathrm{~mL}$ and transferred to $10 \mathrm{~mL}$ volumetric flasks and dissolved by $\mathrm{pH} 7.2$ phosphate buffer-ethanol solvent to achieve concentration of $5 \mu \mathrm{g} / \mathrm{mL}, 9 \mu \mathrm{g} / \mathrm{mL}, 11 \mu \mathrm{g} / \mathrm{mL}$, and $13 \mu \mathrm{g} / \mathrm{mL}$ [2].

\section{Spectral characteristics and wavelength selection}

The absorption spectrum from ACT and $16 \mu \mathrm{g} / \mathrm{mL}$ standard solutions $16 \mu \mathrm{g} / \mathrm{mL}$ IBU, each measured by ultraviolet spectrophotometry wavelength 200-320 $\mathrm{nm}$ and maximum absorption wavelength of ACT and IBU recorded, to be used as a measurement of absorption spectrum for the determination using the CFRS method.

\section{Construction of spectrum ratio}

Saved ACT spectra (3-9 $\mu \mathrm{g} / \mathrm{mL}$ ) were each divided by $9 \mu \mathrm{g} / \mathrm{mL}$ IBU to achieve first ratio spectra mediated by UV Probe, and IBU spectra (5-13 $\mu \mathrm{g} / \mathrm{mL})$ were divided by $8 \mu \mathrm{g} / \mathrm{mL}$ ACT to achieve first ratio spectra mediated by UV Probe. The first ratio spectra of ACT and first ratio spectra of IBU spectra were then made for mean centered using MATLAB software (Mathworks) [9].

\section{Construction of calibration graphs for CFRS}

The centered flat or amplitude values of the first ratio of ACT and IBU ratios at the maximum wavelength obtained were calculated and plotted at $244 \mathrm{~nm}$ and $221 \mathrm{~nm}$ with ACT and IBU concentrations, respectively, to obtain the regression line equation.

\section{Validation test}

The CFRS spectrophotometric method was validated by investigating the following parameters $[16,17]$

\section{Linearity}

Standard solution of ACT and IBU for spectrum absorption was made and measured at the selected wavelength point (244 $\mathrm{nm}$ for ACT and $221 \mathrm{~nm}$ for IBU). The amplitude values of both active substances were determined using the regression equation for each component at its own selected wavelength.

The obtained regression equation general formula is as follows $[16,17]$.

$Y=a x+b$

Notes:

$Y=$ Amplitude

$a=$ Slope

$x=$ Concentration $(\mu \mathrm{g} / \mathrm{mL})$

$b=$ Constant.

\section{Recovery test}

Accuracy was determined using standard addition method by preparing analyte with three specific ranges of $80 \%, 100 \%$, and $120 \%$, with three repetitions each. Every specific range contained 70\% analyte and 30\% standard and then analyzed by the same procedure above. In standard addition method (added the purify active substances), a number of samples analyzed plus analytes with the necessary concentration of the analyte concentration expected, mixed, and analyzed. Differences from the results were compared with the theoretical concentration [16]. In that method, the levels of substances were obtained as the ratio of the obtained results to the theoretical results:

$$
\% \mathrm{R}=\frac{\mathrm{Ca}-\mathrm{Cb}}{\mathrm{Cc}} \times 100 \%
$$

Note:

$\% \mathrm{R}=$ Percentage of recovery

$\mathrm{C}_{\mathrm{a}}=$ Concentration after addition

$\mathrm{C}_{\mathrm{C}}=$ Theoretical concentration before addition

$\mathrm{C}_{\mathrm{b}}=$ Concentration of the standard substances added.

Relative standard deviation (RSD) test

RSD obtained from the regression equation was calculated in the calibration curve with the following formula $[16,17]$ :

$$
\mathrm{RSD}=\frac{\mathrm{SD}}{\overline{\mathrm{X}}} \times 100 \%
$$

Note:

RSD = Relative standard deviation

$\mathrm{SD}=$ Standard deviation

$\bar{X}=$ Average data.

Limit of detection (LOD) and limit of quantification (LOQ) test According to the absorbance at analysis wavelength, LOD and LOQ are counted as follows $[16,17]$.

$$
\mathrm{SD}=\sqrt{\frac{\sum\left(\mathrm{Y}-\mathrm{Y}_{\mathrm{i}}\right)^{2}}{\mathrm{n}-2}}
$$

$$
\begin{aligned}
& \mathrm{LOD}=\frac{3.3 \times \mathrm{SD}}{\text { Slope }} \\
& \mathrm{LOQ}=\frac{10 \times \mathrm{SD}}{\text { Slope }}
\end{aligned}
$$

Note:

$\mathrm{SD}=$ Standard deviation

Slope $=a(y=a x+b)$

Calibration graphs of each ACT and IBU were obtained by plotting the mean center (MC) values versus corresponding concentrations, and the regression equations of ACT and IBU were obtained. 
Preparation of ACT and IBU mixture by self-made

An accurately weighed standard of $50 \mathrm{mg}$ ACT and $50 \mathrm{mg}$ IBU powder was transferred to separate $100 \mathrm{~mL}$ volumetric flasks and dissolved by $\mathrm{pH} 7.2$ phosphate buffer-ethanol solvent mixture. Pippeted $20 \mathrm{~mL}$ of ACT solution and $14 \mathrm{~mL}$ of IBU solution to $50 \mathrm{~mL}$ volumetric flask and dissolved by $\mathrm{pH} 7.2$ phosphate buffer-ethanol solvent mixture until line mark, shaken until homogeneous. Subsequently, the filtrate was accommodated, pipetted $1.75 \mathrm{~mL}$, and transferred to other $50 \mathrm{~mL}$ flask. Standard solution of IBU $(25 \mu \mathrm{g} / \mathrm{mL})$ was pipetted $10 \mathrm{~mL}$ and transferred in a $50 \mathrm{~mL}$ flask and dissolved by $\mathrm{pH} 7.2$ phosphate bufferethanol solvent which contains $1.75 \mathrm{~mL}$ filtrate. The mixture was made up to mark with pH 7.2 phosphate buffer-ethanol solvent mixture to obtain a solution which contained the concentration of $7.0 \mu \mathrm{g} / \mathrm{mL}$ of ACT and $9.0 \mu \mathrm{g} / \mathrm{mL}$ of IBU. The absorption of solution was recorded in the wavelength range $200-400 \mathrm{~nm}$. Then, the same procedure of construction of ratio spectra and centered average on spectrum ratio was used [15].

\section{Determination of ACT and IBU mixture in pharmaceutical tablet}

Twenty tablets were weighed and powdered in a mortar. Furthermore, a number of weighed powder equivalent to $10 \mathrm{mg}$ of ACT and IBU was calculated based on the equality to ACT (weighing powders were repeated 6 times). Subsequently transferred in a $50 \mathrm{~mL}$ volumemetric flask, and dissolved by solvent of $\mathrm{pH} 7.2$ phosphate buffer-ethanol (homogenized with sonicator for $15 \mathrm{~min}$ ), and then were made up with pH 7.2 phosphate buffer-ethanol solvent until the line mark, shaken until homogeneous. The solution was then filtered, approximately $10 \mathrm{~mL}$ of the first filtrate discarded. Subsequently, the filtrate was accommodated, pipetted $1.75 \mathrm{~mL}$, and transferred in an other $50 \mathrm{~mL}$ flask. Standard solution of IBU (25 $\mu \mathrm{g} / \mathrm{mL})$ was pipetted $10 \mathrm{~mL}$, transferred in a $50 \mathrm{~mL}$ flask, and dissolved by $\mathrm{pH} 7.2$ phosphate bufferethanol solvent which contains $1.75 \mathrm{~mL}$ filtrate. The mixture was made up to mark with $\mathrm{pH} 7.2$ phosphate buffer-ethanol solvent mixture to obtain a solution which contained the concentration of $7.0 \mu \mathrm{g} / \mathrm{mL}$ of ACT and $9.0 \mu \mathrm{g} / \mathrm{mL}$ of IBU. The absorption of solution was recorded in the wavelength range $200-400 \mathrm{~nm}$. To obtain the MC values of each ACT and IBU in tablet, the same procedure above (construction of ratio spectra and centered on ratio spectra) was used $[9,15]$.

\section{RESULTS AND DISCUSSION}

The creation of CFRS from ACT and IBU based on mathematical equations exemplified by Afkhami and Bahram that MCR methods can be used for the simultaneous determination of binary and ternary mixtures without the separation. That to explain the MC expression, the vector is exemplified as follows [9]:

$y=\left[\begin{array}{l}5 \\ 1 \\ 3\end{array}\right]$

The MC of the above vector was be done by subtracting from the above three-digit averages, such as

$$
\begin{aligned}
& \bar{y}=\left[\begin{array}{l}
3 \\
3 \\
3
\end{array}\right] \\
& M C(y)=y-\bar{y}=\left[\begin{array}{l}
5 \\
1 \\
3
\end{array}\right]-\left[\begin{array}{l}
3 \\
3 \\
3
\end{array}\right]=\left[\begin{array}{c}
+2 \\
-2 \\
0
\end{array}\right]
\end{aligned}
$$

It is assumed that the mixture contains three compounds $\mathrm{X}, \mathrm{Y}$, and $\mathrm{Z}$. If there is no interaction between the compounds, then the mathematical equation is as follows:
$A m=\alpha x C X+\alpha y C Y+\alpha z C Z$

Where $A m$ is a vector of mixed absorbance, $\alpha x, \alpha y$, and $\alpha z$ are molar absorptivity vectors of $X, Y$, and $Z$, and $C X, C y$, and $C Z$ are concentrations of $X, Y$, and $Z$. If the equation (1) divided by $\alpha Z$ is the spectrum of standard solution $Z$, then the first ratio spectrum is obtained by equation (2) with note if the az value is 0 , this value cannot be used as a dividing factor [9].

$\mathrm{B}=\frac{\mathrm{Am}}{\alpha \mathrm{Z}}=\frac{\alpha \mathrm{XCX}}{\alpha \mathrm{Z}}+\frac{\alpha \mathrm{YCY}}{\alpha \mathrm{Z}}+\mathrm{CZ}$

If equation (2) is made $\mathrm{MC}$, since the $\mathrm{MC}$ constant value is 0 , then the equation (3) is obtained:

$\mathrm{MC}(\mathrm{B})=\mathrm{MC}\left[\frac{\alpha \mathrm{XCX}}{\alpha \mathrm{Z}}\right]+\mathrm{MC}\left[\frac{\alpha \mathrm{YCY}}{\alpha \mathrm{Z}}\right]$

By dividing equation (3) with $\mathrm{MC}(\alpha Y / \alpha Z)$, corresponding to the centered average on spectrum ratio of standard solutions $Y$ and $Z$, the second ratio spectrum is obtained as follows (4):

$\mathrm{D}=\frac{\mathrm{MC}(\mathrm{B})}{\mathrm{MC}(\alpha \mathrm{Y} / \alpha \mathrm{Z})}=\frac{\mathrm{MC}\left[\frac{\alpha \mathrm{XCX}}{\alpha \mathrm{Z}}\right]}{\mathrm{MC}(\alpha \mathrm{Y} / \alpha \mathrm{Z})}+\mathrm{CY}$

If equation (4) is in $\mathrm{MC}$, since the $\mathrm{MC}$ constant $(\mathrm{CY})$ is 0 , the equation is obtained:

$\operatorname{MC}(\mathrm{D})=\mathrm{MC} \frac{\mathrm{MC}\left[\frac{\alpha \mathrm{XCX}}{\alpha \mathrm{Z}}\right]}{\operatorname{MC}(\alpha \mathrm{Y} / \alpha \mathrm{Z})}$

Equation (5) shows that there is a linear relationship between the number of $M C(D)$ and the $\mathrm{X}$ concentration in the solution. Then, the calibration curve can be made by plotting $(D)$ against the $X$ concentration from the $X$ standard solution in the mixture [9].

Optimization of absorption spectrum conditions for CFRS method Molecular absorption methods in UV spectrophotometry have been widely used for the determination of drug levels in pharmaceutical preparations, especially in developing simpler, faster, and more reliable analytical methods [2]. This technique can be used for pharmaceutical analysis to have an inherent constraint since most of the active drug mixture has a spectrum adjacent to the UV area and overlap making it difficult to determine the simultaneous level of the mixture [3].

The maximum absorption of ACT and IBU spectrum is overlapped, and the result of the overlap can be seen in Fig. 2 .

Based on Fig. 2, it can be seen that the results of maximum absorption spectrum were done at wavelength range 200-400 nm that maximum wavelength of ACT in pH 7.2 phosphate buffer-ethanol (91:9) was $244 \mathrm{~nm}$ and IBU was $222 \mathrm{~nm}$ [15]. Construction of Fig. 2 was made by combining a spectrum of ACT $(6.6 \mu \mathrm{g} / \mathrm{mL})$ and IBU $(8.0 \mu \mathrm{g} / \mathrm{mL})$.

It showed that most of the IBU absorption spectrum was overlapped by ACT absorption spectrum so that direct spectrophotometric method was unable to be used to determine ACT and IBU mixture. Differ from direct spectrophotometric method, CFRS method was able to determine ACT and IBU mixture.

Construction of ACT and IBU absorption spectra at various concentrations

The stability of the absorption of ACT and IBU in $\mathrm{pH} 7.2$ phosphate buffer and ethanol (91:9) mixed solvent has been made by measurement of the absorption of the standard solution with varying concentrations. The absorption spectrum of various concentrations can be seen in Figs. 3 and 4 . 
Based on Figs. 3 and 4, it can be seen that ACT and IBU spectra in pH 7.2 phosphate buffer-ethanol (91:9) solvent mixture showed that concentration did not change the spectra so that solvent mixture usage was stable against for ACT and IBU solution.

That means measurements in accordance with The fourth edition of the Indonesian Pharmacopoeia that the use of solvents is permitted in spectrophotometric method if the solvent only changes the maximum wavelength of the component of the drug, if it is not more than $3 \%$ of the wavelength stated in the literature [2].

\section{Construction spectrum of ratio from CFRS}

The CFRS method constructed by reference to previous research on the developed MCR method depends on the centralized average of the resulting spectrum ratio [9], which eliminates the derivative steps, and therefore, the signal-to-noise ratio is increased [9]. To optimize the developed CFRS technique, several different parameters are tested. Among other wavelengths taken will have a large influence on the MC ratio spectrum obtained, different wavelength ranges are then tested and the best results were obtained using a wavelength range from 200 to $300 \mathrm{~nm}$ and 200 to $280 \mathrm{~nm}$, respectively, for ACT and IBU. The influence of the divisor concentration on the selectivity of the method has been tested.

Different concentrations of each ACT and IBU were tested. It was found that the divisor concentration had no significant effect on the specificity<smiles>CC(=O)Nc1ccc(O)cc1</smiles>

Fig. 1: The chemical structure of structure acetaminophen (a) and structure of ibuprofen (b) [2]

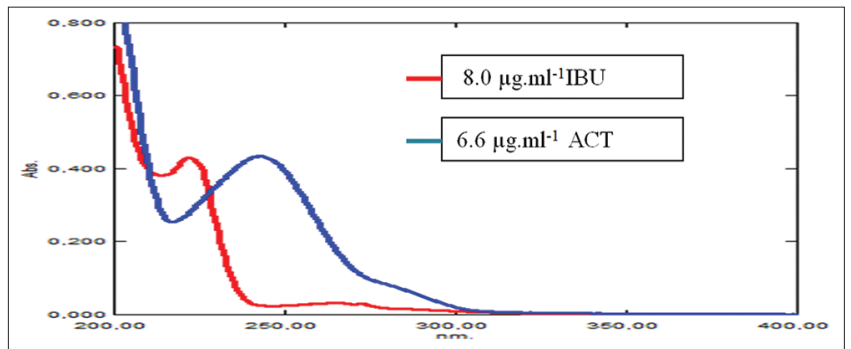

Fig. 2: Overlapping absorption spectrum of acetaminophen and ibuprofen

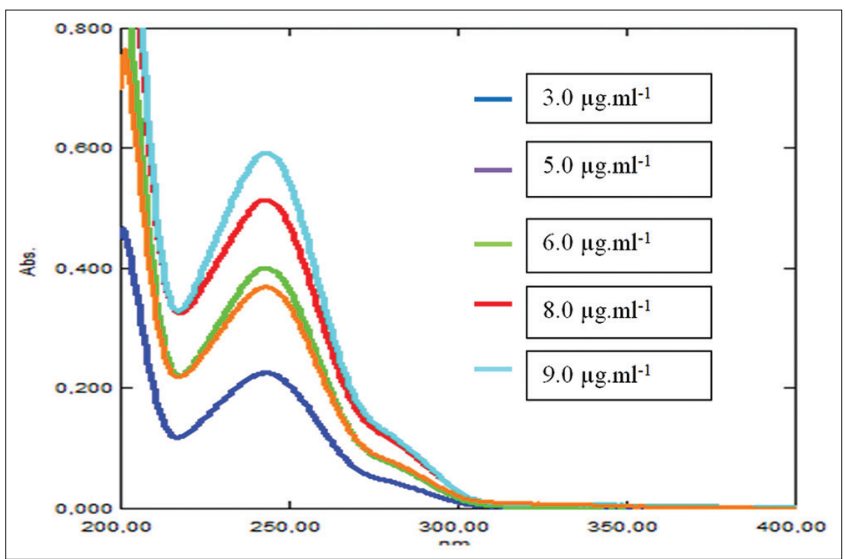

Fig. 3: Absorption spectra of acetaminophen at various concentrations of the determination of ACT and IBU, and therefore, the normalized spectra of each ACT and IBU were used as a divisor.

As shown in Fig. 2, the absorption spectra of ACT and IBU appear to overlap. In this case, the absorption spectra of ACT standard solutions of different concentrations are recorded in the wavelength range of 200-300 nm and divided by the normalized IBU spectrum, and the ratio spectrum obtained is the MC. Similarly, for the determination of IBU, the absorption spectra of standard IBU solutions of different concentrations were recorded in the wavelength range of 200-280 nm and divided by the normal spectrum of ACT and the average centered ratio spectrum (Fig. 5). The concentration of IBU is determined by measuring the amplitude at $244.0 \mathrm{~nm}$ according to the maximum wavelength as shown in the same figure.

In CFRS spectrophotometric technique, it was begun by constructing ratio spectra and divisor concentration determination. Divisor concentration was chosen from the concentration range for LambertBeer law compliance.

The tablet sample that will be determined is the content of ACT and IBU has a ratio of $7: 4$ while the compilation of the determination of ACT concentration spectrophotometry is $8.0 \mu \mathrm{g} / \mathrm{mL}$ and 4.57 $\mu \mathrm{g} / \mathrm{mL}$ ibuprofen, because based on the concentration of Ibuprufen measurement below the minimum limit of absorbance below 02 , so that it is added additively using a standard solution so that the measured concentration is in the absorbance area according to the requirements of the Lambert Beer law that is absorbance in the area of

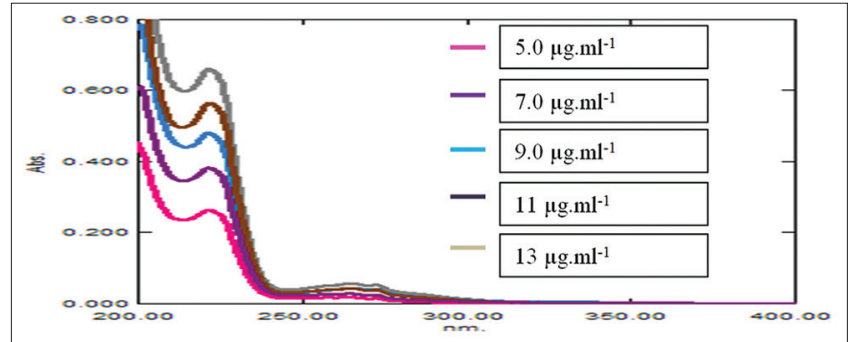

Fig. 4: Absorption spectra of ibuprofen at various concentrations

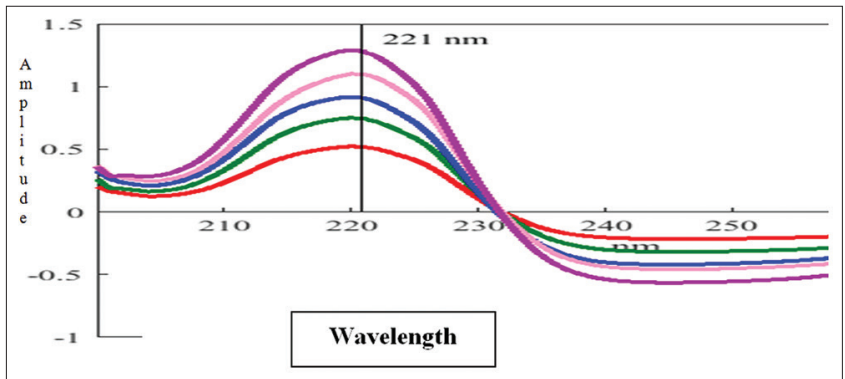

Fig. 5: Means centered on the spectrum ratio of the ibuprofen

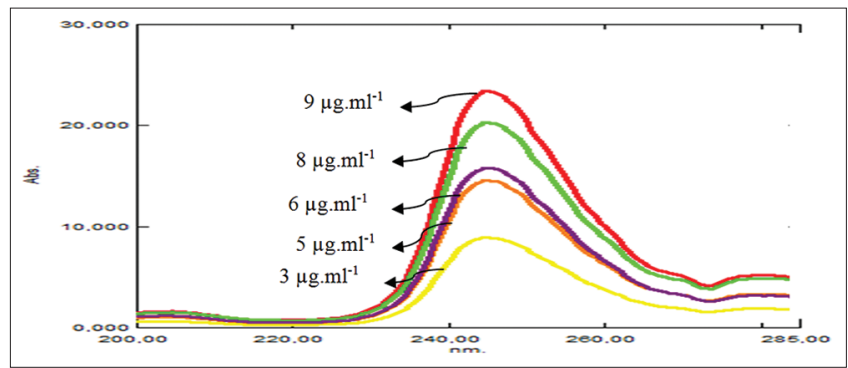

Fig. 6: Ratio absorption spectrum of acetaminophen with $9.0 \mu \mathrm{g} / \mathrm{mL}$ ibuprofen as divisor 
0.2-0.6.Besides that the concentration of IBU was $4.43 \mu \mathrm{g} / \mathrm{mL}$ to be in the area absorbance 0.4343 .

Concentration of ACT used in this experiment was $8.0 \mu \mathrm{g} / \mathrm{mL}$ and IBU $9.0 \mu \mathrm{g} / \mathrm{mL}$. Ratio spectra were done to diminish the effect of other substance and must not contain zero absorption value [8]. The results can be seen in the Figs. 6 and 7.

\section{Result of MC value for ACT and IBU}

Result of the maximum wavelength of ACT and IBU and their MC values can be seen in Figs. 5 and 8.

\section{ACT and IBU calibration curve}

Calibration curve in CFRS method is constructed by concentrations versus amplitude (MC results) graph. Regression equation that obtained using CFRS method for ACT is as follows:

$M C_{A C T}=1.58 \mathrm{C}+0.4809$

$r=0.9963$

And for IBU is:

$M C_{I B U}=0.991 \mathrm{C}+0.0205$

$r=0.9990$

Note:

$C=$ The concentration in $\mu \mathrm{g} / \mathrm{mL}$

$M C=$ Mean centered value,

$r=$ Correlation coefficient.

It is mean that the calibration curve of CFRS has a linear regression because the value of correlation coefficient which is $>0.97$ shows that there is a linear correlation between concentration and amplitude.

\section{Results of validation test}

The average of percentage recovery for both ACT and IBU was $100.01 \%$ and $100.31 \%$, respectively. These values fulfilled the accuracy requirement such as $98-102 \%$ [2].

The RSD of both ACT and IBU was $0.03 \%$ and $0.06 \%$, respectively, and fulfilled precision requirement such as $<2 \%[13,14]$. LOD and LOQ for

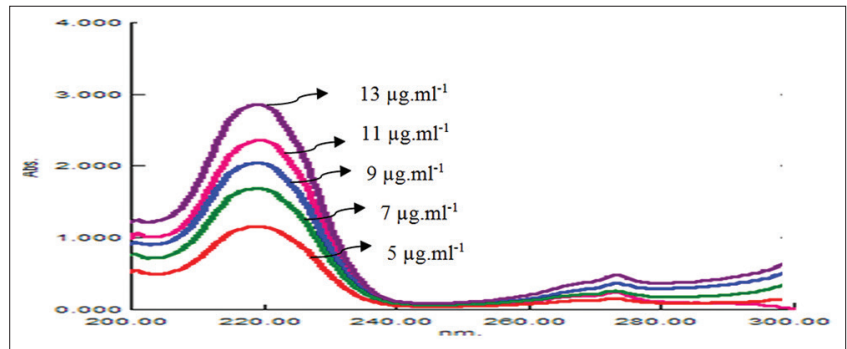

Fig. 7: Ratio absorption spectrum of ibuprofen with $8.0 \mu \mathrm{g} / \mathrm{mL}$ acetaminophen as divisor

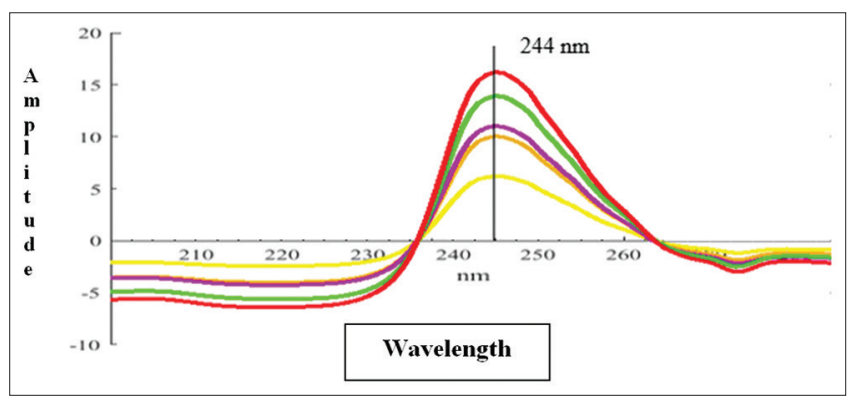

Fig. 8: Means centered on the spectrum ratio of the acetaminophen
ACT were $0.843 \mu \mathrm{g} / \mathrm{mL}$ and $2.811 \mu \mathrm{g} / \mathrm{mL}$, respectively, while for IBU were $0.636 \mu \mathrm{g} / \mathrm{mL}$ and $2.119 \mu \mathrm{g} / \mathrm{mL}$, respectively. Based on the results above, it can be stated that the CFRS method has good accuracy and precision, besides that from the above results it can be seen that all measurements carried out are in the 0.2-0.6 absorption area which means that the sample measurements are also above the detection limit and the quantitation limit [17]

Therefore, it can be concluded that the CFRS method has met the method validation requirements, in determining the levels of ACT and IBU and also in accordance with publications from various other researchers using the Mean Centered Ratio spectra method that uses various mixtures of drugs with different solvents have validity with parameters, accuracy, precision, linearity, LOD and LOQ [9,10-13,14].

\section{Determination of ACT and IBU in sample}

Preparation samples solution of made by self-made and brand tablet was conduct done by standard addition method because the concentration of IBU during measurement is too small so it needs to use the standard addition method so that its IBU can be measured fulfill Lambert Beer's law.

Preparation of sample solution from brand tablets by dissolving the sample in solvent ethanol- $\mathrm{pH} 7.2$ buffer phosphate and measuring the absorption spectrum at a wavelength of $200-400 \mathrm{~nm}$ to obtain the sample absorption spectrum. Then, the spectrum was divided by a predetermined divisor to obtain the ratio spectrum of each drug. Then, the ratio spectra of the ACT and IBU are filtered by the MATLAB

Table 1: MC values of ACT and IBU on tablet

\begin{tabular}{lll}
\hline \multirow{2}{*}{ Repetition } & \multicolumn{1}{l}{$\boldsymbol{M C}$ values $(\boldsymbol{Y})$} & \\
\cline { 2 - 3 } & ACT & IBU \\
\hline 1. & 11.6377 & 0.4138 \\
2. & 11.6365 & 0.4142 \\
3. & 11.5864 & 0.4129 \\
4. & 11.5735 & 0.4130 \\
5. & 11.5719 & 0.4126 \\
6. & 11.6253 & 0.4135 \\
\hline
\end{tabular}

MC: Mean center, ACT: Acetaminophen, IBU: Ibuprofen

Table 2: Theoretical and practice concentrations of ACT

\begin{tabular}{llll}
\hline Repetition & $\begin{array}{l}\text { MC value } \\
\text { of ACT }\end{array}$ & $\begin{array}{l}\text { Practice } \\
\text { concentration of } \\
\text { ACT }(\boldsymbol{\mu g} / \mathbf{m L})\end{array}$ & $\begin{array}{l}\text { Theoretical } \\
\text { concentration of } \\
\text { ACT }(\boldsymbol{\mu g} / \mathbf{m L})\end{array}$ \\
\hline 1. & 11.6377 & 7.0613 & 7.0247 \\
2. & 11.6365 & 7.0605 & 7.0247 \\
3. & 11.5864 & 7.0288 & 7.0087 \\
4. & 11.5735 & 7.0206 & 6.9995 \\
5. & 11.5719 & 7.0196 & 6.9970 \\
6. & 11.6253 & 7.0534 & 7.0176 \\
\hline
\end{tabular}

MC: Mean center, ACT: Acetaminophen, IBU: Ibuprofen

Table 3: Theoretical and practice concentrations of IBU

\begin{tabular}{llll}
\hline Repetition & $\begin{array}{l}\text { MC value } \\
\text { of IBU }\end{array}$ & $\begin{array}{l}\text { Practice } \\
\text { concentration of } \\
\text { IBU }(\boldsymbol{\mu g} / \mathbf{m L})\end{array}$ & $\begin{array}{l}\text { Theoretical } \\
\text { concentration of } \\
\text { IBU }(\boldsymbol{\mu g} / \mathbf{m L})\end{array}$ \\
\hline 1. & 0.4138 & 3.9692 & 4.0141 \\
2. & 0.4142 & 3.9733 & 4.0141 \\
3. & 0.4129 & 3.9601 & 4.0051 \\
4. & 0.4130 & 3.9612 & 3.9996 \\
5. & 0.4126 & 3.9571 & 3.9983 \\
6. & 0.4135 & 3.9662 & 4.0100 \\
\hline
\end{tabular}


Table 4: Levels of ACT and IBU

\begin{tabular}{llll}
\hline No & $\begin{array}{l}\text { Component of } \\
\text { drug }\end{array}$ & Self-made (mg) & $\begin{array}{l}\text { Tablet pharmaceutical } \\
\text { form (mg) }\end{array}$ \\
\hline 1. & Acetominophen & $350.10 \pm 0.15$ & $352.52 \pm 0.42$ \\
2. & IBU & $199.74 \pm 0.28$ & $197.64 \pm 0.12$ \\
\hline
\end{tabular}

ACT: Acetaminophen, IBU: Ibuprofen

application to obtain the MC value, and then, calculated the rate obtained using the regression equation.

In determining the sample rate, it is taken the amplitude value at the maximum peak that has been directed and then inserted into the regression equation that has been obtained previously. The data MC value of ACT and IBU on tablet is summarized in Table 1, and the results of theoretical and practice concentrations of ACT and IBU are given in Tables 2 and 3. The result of statiscally determining ACT and IBU in brand tablets is given in Table 4 .

Based on Tables 1-4, it can be seen that the results of measurements of a self-made and local product were not significant by statistical test and meet the requirements contained in Indonesian Pharmacopeia $5^{\text {th }}$ edition (2014). It is mean that the assay methods of CFRS can be used for simultaneous determination of ACT and IBU in tablet dosage form.

\section{CONCLUSION}

The centered flat of ratio spectra is a swift, exact, and fixed quantitative spectrophotometric technique and has been implemented in the determination of ACT and IBU in laboratory working and pharmaceutical tablet. The levels of ACT and IBU in tablet were $100.72 \pm 0.12 \%$ and $98.82 \pm 0.06 \%$, respectively, and fulfilled accuracy and precision requirements with average percentage recovery of $100.01 \%$ and $100.31 \%$, also RSD values of $0.03 \%$ and $0.06 \%$, respectively.

\section{AUTHORS' CONTRIBUTION}

The first author to design and formulate research and publish articles. The second author performs and discusses the results of the data analysis. The third author prepares the implementation of the research procedure directed by the first author.

\section{CONFLICTS OF INTEREST}

We declare that there are no conflicts of interest.

\section{REFERENCES}

1. Tan HT, Rahardja K. Essential Drugs: Benefits, Uses and Side Effects. Jakarta: PT Elex Media Komputindo; 2007.
2. Indonesian Health Ministry. Indonesian Pharmacopoeia. $5^{\text {th }}$ ed. Jakarta: Indonesian Health Ministry; 2014. p. 449-50, 650-51.

3. Damayanti S, Ibrahim S, Firman K, Tjahjono DH. Determination of paracetamol and ibuprofen mexture with derivative spectrophotometry. Ind J Chem 2003;3:9-13.

4. Vijay DC, Nejal MB, Mallika S, Pranav SS. Comparative evaluation of first order, absorbance ratio and bivariate spectrophotometric methods for determination of atovaquone and proguanil in pharmaceutical formulation malarone. Int J Pharm Pharm Sci 2015;7:165-71.

5. Seema S, Bhavesh P. Implementation of qbd approach to develop and validate analytical method for simultaneous estimation of duloxetine hydrochloride and methylcobalamin in pharmaceutical dosage form by hptlc method. Int J Phar Pharm Sci 2016;8:105-17.

6. Masimukku SK, Chintala R. Development and validation of spectrophotometric methods for simultaneous estimation of vilanterol and fluticasone furoate in pharmaceutical formulations. Asian J Pharm Clin Res 2017;10:302-5.

7. Mohsen AM, Lotfy HM, Badawey AM, Salem H, Elkhateeb SZ. Application of three novel spectrophotometric methods manipulating ratio spectra for resolving a pharmaceutical mixture of chlorphenoxamine hydrochloride and caffeine. Int J Pharm Pharma Sci 2013;5:478-87.

8. Bhatia NM, Desai RB, Jadhav SD. Simultaneous estimation of losartan potassium and hydrochlorothiazide from tablets by first order derivative spectroscopy. Int J Pharm Pharm Sci 2013;5:464-6.

9. Afkhami A, Bahram. Mean centering of ratio spectra as a new spectrophotometric method for the analysis of binary and ternary mixtures. Talanta 2005;66:712-20.

10. Hoang VD. Simultaneous determination of paracetamol and caffeine in tablets by mean centering and derivative transforms of Uv ratio spectra. Asian J Res Chem 2014;7:561-4.

11. Issa YM, Zayed SI, Habib IH. Simultaneous determination of ibuprofen and paracetamol using derivatives of the ratio spectra method. Arab J Chem 2011;4:259-63.

12. Lotfy HM, Amer SM, Zaazaa HE, Mostafa NS. Spectrophotometric methods for quantitative determination of binary mixture of naproxen sodium and domperidone maleate. Austin J Anal Pharm Chem 2015;2:1-8.

13. An DT, Hoang VD. Simultaneous determination of paracetamol and codeine phosphate in combined tablets by first-order derivative and ratio spectra first-order derivative Uv spectrophotometry. Asian J Res Chem 2009;2:143-7.

14. Darwish HW, Hassan SA, Salem MY, El-Zeiny BA. Three different spectrophotometric methods manipulating ratio spectra for determination of binary mixture of amlodipine and atorvastatin. Spectrochim Acta A Mol Biomol Spectrosc 2011;83:140-8.

15. Saraan SM, Sinaga SM, Muchlisyam. Development method for determination of ternary mixture of paracetamol, ibuprofen, and caffeine in tablet dosage form using zero-crossing derivative spectrophotometry. Int J Pharm Tech Res 2015;7:349-53.

16. Sudjana E. Statistic Method. Bandung: Tartiso Press; 2005. p. 93, 145, 201, 225.

17. Harmita F. Implementation Guidelines and the Calculation Method Validation. Jakarta: Pharmaceutial Science Magazine; 2004. p. 118-20. 